\title{
TRANSACTIVATION OF THE HUMAN C-MYC GENE BY C-MYB
}

\author{
Andrea Zobel*, Frank Kalkbrenner*, Gerd Vorbrueggen and Karin Moelling ${ }^{+}$ \\ Max-Planck-Institut fuer Molekulare Genetik, Abt. Schuster, Innestrasse 73, \\ D-1000 Berlin 33, Germany
}

Received June 5, 1992

Summary: We analyse the contribution of six Myb-binding sites in the upstream c-myc sequences to transactivation by co-transfection assays. Surprisingly, deletion of the six Myb-binding sites did not influence the transactivation of c-myc by c-Myb protein. Instead, the strongest transactivation was observed with a c-myc reporter plasmid which contains only 450 bp of exon 1 including the c-myc promoter P2. An exchange of the DNA binding domain of c-Myb by that of GAL4 led only to small transactivation effects indicating that the DNA binding domain of $\mathrm{c}-\mathrm{Myb}$ is essential for transactivation of the $\mathrm{c}-\mathrm{myc}$ gene. These results suggest either an indirect transactivation mechanism of the c-myc gene by c-Myb proteins or a role of the DNA binding domain for additional effects than DNA binding.

c 1992 Academic press, Inc.

The protooncogene products $\mathrm{c}-\mathrm{Myb}$ and $\mathrm{c}-\mathrm{Myc}$ are expressed in immature cells whereby expression of c-myc is more ubiquitous than that of c-myb which is restricted to cells of lymphoid, erythroid and myeloid lineages $(1,2,3)$ and a number of other tissues (4). Both, the expression of $\mathrm{c}-\mathrm{Myc}$ and $\mathrm{c}-\mathrm{Myb}$ is coupled to the proliferation and differentiation state of eucaryotic cells (5-10). Direct evidence that c-myc expression is influenced by c-Myb came from the result, that an overexpression of exogenous $\mathrm{c}-\mathrm{Myb}$ in certain leukemic CTLL-2 cells led to an increase of endogenous c-myc expression (11).

Investigations of $c-m y c$ regulation have shown previously that transcription of this gene is regulated both, by positive and negative elements located upstream and downstream of the main c-myc promoters but only a few transcription factors have been identified so far (for review see 12).

Both $\mathrm{v}-\mathrm{Myb}$ and $\mathrm{c}-\mathrm{Myb}$ are transcriptional activators containing an acidic transactivation domain $(13,14,15)$. The $v$-Myb protein is able to bind specifically the DNA sequence PyAACT/GG (16). In a previous study (17) we have shown that the c-Myb protein binds the sequences AACVGTT or AACGTT (V: A, C, G or T). Recently the Myb-binding sequence has been extended to CPyAACVGPyCPu using a sensitive PCR method in which

* Present address: Institut fuer Pharmakologie der Freien Universitaet Berlin, Thielallee 69/73, D-1000 Berlin 33, Germany.

+To whom correspondence should be addressed. 
DNA oligomers with a random nucleotide core were used (18). Both, c- and v-Myb proteins, transactivate artificial promoter constructs containing multimers of this Mybbinding site $(14,19-22)$. Moreover, the promoter region of the first identified v-Mybregulated gene, mim-1, contains three Myb-binding sites (20), indicating that Myb transactivates the mim-1 gene.

We have described various Myb-binding sites in the regulatory region of the human c-myc gene and have shown that the human $\mathrm{c}-\mathrm{Myb}$ protein is able to transactivate the c-myc gene in cells in culture (17). In order to define the contribution of the Myb-binding sites to this transactivation effect we constructed a series of mutated c-myc promoter regions linked to the chloramphenicol acetyl transferase (CAT) gene. Co-transfections of these reporter plasmids with Myb-expressing effector plasmids into COS recipient cells revealed, that the transactivation of c-myc transcription by $\mathrm{c}-\mathrm{Myb}$ is independent of the presence of highaffinity Myb-binding sites in the 5' flanking sequence of the c-myc gene. Nevertheless the transactivation effect requires the presence of the DNA binding domain of the $c-\mathrm{Myb}$ protein.

\section{MATERIALS AND METHODS}

Effector plasmids. As effector plasmids the plasmid pHM1, expressing the full-length human $\mathrm{c}-\mathrm{Myb}$ protein $\mathrm{p} 75$, the plasmid $\mathrm{pHM} 5$, expressing the carboxy-terminally deleted human c-Myb protein p42 (amino acid residues 1-358) (17) and the plasmid pGM5, expressing a GAL4-c-Myb fusion protein, in which the DN $\Lambda$ binding domain of $\mathrm{p} 42 \mathrm{c}-\mathrm{Myb}$ was exchanged by the DNA binding domain of GALA (amino acid residues 1-83 of GAL4 fused to amino acid residues 201-358 of c-Myb) (15) were used. The SV40 derived expression vector pECE (23) without any insert served as negative control.

Reporter plasmids. Internally deleted mutants of the plasmid p2.3mycCAT (24), containing the upstream regulatory sequences of hu-c-myc, were created by restriction of the appropriate fragments. Both ends were filled in with T4 DNA polymerase and ligated. For construction of the plasmid p2.3PAmycCAT the SV40 poly A-sequence derived from the plasmid pECE was inserted into the SmaI site of $\mathrm{p} 2.3$ mycCAT upstream of the c-myc promoter P1. Mutations of the Myb-binding site between promoter P2 and the TATA box were obtained by using the PCR technique. A BIOMED thermocycler and Taq-polymerase from Promega were used according to the instructions of the manufacturers. The nucleotides $G,+144$ and $C,+145$ (numbered relative to the transcription start of P1) were mutated to $\mathrm{C}$ and $\mathrm{A}$ by using primers creating a DNA fragment that included the TATA box and part of the exon 1 up to the RsrII site, whereby one primer contains the mutations. The first PCR product was used as primer in a second PCR together with a primer binding near the XhoI site upstream of the TATA box. The second PCR product was restricted with XhoI and RsrII and inserted into the RsrII-XhoI deleted plasmid p1.2mycCAT. The resulting plasmid $\mathrm{p} 1.2^{\mathrm{mut}_{\mathrm{t}}} \mathrm{ycCAT}$ was controlled by sequencing and ClaI-XhoI-deleted to create the plasmid $\mathrm{p} \Delta \mathrm{P} 1^{\text {mut }}$ mycCAT.

DNA transfection. DNA transfection was performed by calcium phosphate precipitation (25) into COS-7 recipient cells which were about $50 \%$ confluent. Effector and reporter plasmids were transfected in relative amounts of 19 to $1(19 \mu \mathrm{g}$ and $1 \mu \mathrm{g}$ of DNA, respectively, per $5 \times 10^{5}$ cells). Cells were harvested $48 \mathrm{~h}$ after transfection and CAT activity was measured by determination of butyrylated $\left[{ }^{14} \mathrm{C}\right]$ chloramphenicol (chloramphenicol $40-60 \mathrm{mCi} / \mathrm{mmol}, 0.05 \mu \mathrm{Ci}$ per assay) after phase extraction with two volumes of a 2:1 mixture of tetramethylpentadecane (TMPD) and xylene (26). Radioactivity was measured by liquid scintillation counting. CAT assay was performed in all cases with $60 \mu \mathrm{g}$ ccllular lysate incubated for 60 minutes. 


\section{RESULTS}

The regulatory region of the human c-myc gene contains a number of Myb-binding sites. In a previous study (17) we showed that $\mathrm{c}-\mathrm{Myb}$ binds these sites in vitro using partially purified bacterially expressed c- and v-Myb proteins in gel retardation assays and DNAaseI footprinting experiments. Fig.1A schematically shows the positions of six Myb-binding sites on the 5' flanking sequences of the c-myc gene. Furthermore, the c-myc sequences protected by $\mathrm{c}-\mathrm{Myb}$ proteins in DNAasel footprinting experiments are listed and the binding affinities of the $\mathrm{c}-\mathrm{Myb}$ proteins to these six Myb-binding sites are indicated as published previously (17, Fig.1B).

To investigate the functional significance of the six Myb-binding sites for c-myc expression, transactivation studies were performed. Based on the reporter plasmid p2.3mycCAT (24), that contains $2.3 \mathrm{kbp}$ of the 5 ' flanking sequences of the human $\mathrm{c}$-myc gene, including exon 1 , fused upstream of a chloramphenicol acetyl transferase (CAT) gene we prepared mutant plasmids with internal deletions, insertions or mutations affecting Myb-binding sites (Fig.2A). In order to determine the basal transactivation of each reporter plasmid cotransfections with pECE, an SV40-derived expression vector without insert (23) were performed. The reporter plasmids were co-transfected into COS recipient cells with pECE derived effector plasmids expressing either the full-length c-Myb protein p75 c-Myb (pHM1), a carboxy-terminally deleted c-Myb protein p42 c-Myb (pHM5) (17) or a GAL4-

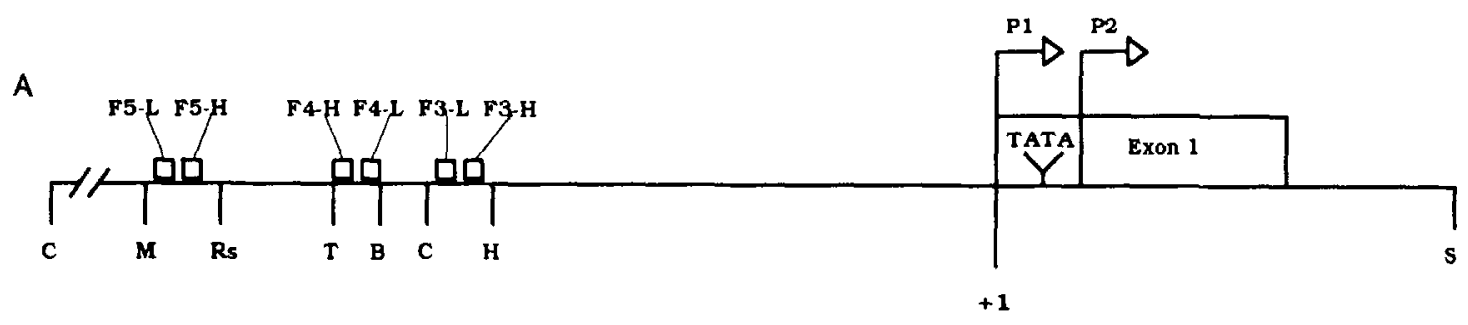

B

$\begin{array}{llc}\text { c-Myb-binding site_Sequence } & \text { Binding affinity } \\ \text { F5-L } & \text { GAATTGTGCAGTGCATCGGATTTGGAAG } & +/- \\ \text { F5-H } & \text { AAACTCAACGGGTAATAA } & + \\ \text { F4-H } & \text { GAATACACGTTTGCGGGTTACA } & + \\ \text { F4-L } & \text { AGAAAAAATTGTGAGTCAGTG } & +1- \\ \text { F3-L } & \text { GAATTAAACGGTCCGGT } & + \\ \text { F3-H } & \text { AGAGTTAACGGTTTTTT } & ++\end{array}$

Fig.1. (A) The positions of six Myb-binding sites on the 5' flanking sequences of the human c-myc gene are indicated by boxes. Previously published Myb-binding sites are designated as F5-H, F5-L, F4-H, F4-L, F3-H and F3-L whereby $\mathrm{L}$ indicates low and $\mathrm{H}$ high affinity binding sites (17). Restriction sites are abbreviated as follows, C: ClaI, M: MvnI, Rs: RsaI, T: TaqI, B: BglI, H: Hinfl, S: SstI. P1, P2, c-myc promoters. Start of transcription of $P 1$ is indicated by +1 . (B) The sequences of the six Myb-binding sites are derived from DNAasel footprinting experiments and the relative binding affinities $(+++$ : high; + : intermediate; $+1-$ : low) have been determined previously in comparative gel retardation assays (17). Nucleotides corresponding to the c-Myb-consensus sequence TAACVGTT or TAACGTT (17) are underlined. Nucleotides corresponding to the Mybconsensus sequence CPyAACVGPyCPu (18) are indicated by bold letters. 
m
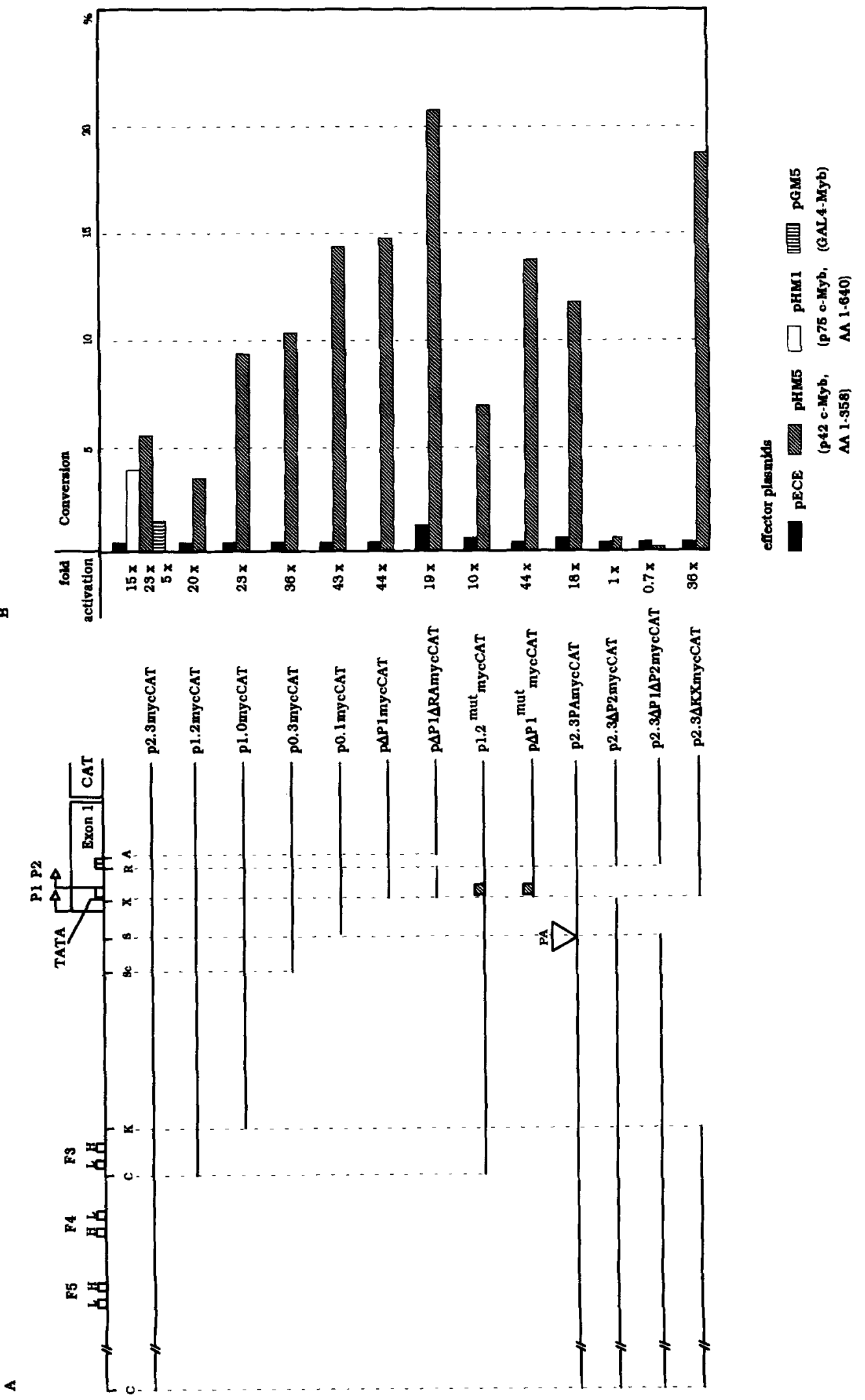
Myb fusion protein (pGM5), consisting of a p42 c-Myb protein which DNA binding domain had been replaced by the DNA binding domain of the GALA protein (15). Fold activation refers to the basal transactivation activities of the reporter plasmids.

In comparison to the basal activities of the reporter plasmids strong positive transactivation effects were generated by the c-Myb expressing constructs (Fig.2B). The full-length reporter plasmid $\mathrm{p} 2.3$ mycCAT generated strong positive transactivation effects with pHM1 and pHM5 but only a small transactivation effect with pGM5. Deletions of the Myb-binding sites F5-H, F5-L, F4-H and F4-L resulted in the reporter plasmid p1.2mycCAT (Fig.2B). Co-transfection of this plasmid with pHM5 resulted in a slightly lower transactivation effect than that obtained with p2.3mycCAT, indicating that the deleted Myb-binding sites contribute to the transactivation of c-myc. Surprisingly, deletion of the two Myb-binding sites F3-H and F3-L with high and intermediate affinities (reporter plasmid p1.0mycCAT) led to a transactivation similar to that obtained with the full-length p2.3mycCAT. Further deletions of the $5^{\prime}$ flanking sequences (reporter plasmids p0.3mycCAT and p0.1mycCAT) resulted in further increase of the transactivation effects. The highest transactivation effect (44 fold) was obtained with the reporter plasmid $\mathrm{p} \Delta \mathrm{P} 1$ mycCAT, containing only the c-myc promoter $\mathrm{P} 2$ and 100 bp upstream plus downstream sequences.

We noticed in addition to the six published Myb-binding sites potential other sites in exon 1 downstream of P2 between the RsrII and AvaI restriction sites (CAACCCTT, AAACTTTG, GAACTTAC) (indicated by boxes in Fig.2A) and between the TATA box and the transcription start of P2 (GCCGGTTT) (indicated by box next P2 in Fig.2A). In gel retardation assays and DNAaseI footprinting experiments binding with low and intermediate affinities of $\mathrm{c}-\mathrm{Myb}$ proteins to these sequences have been observed (data not shown). Deletion of the Myb-binding sites downstream of P2 inside exon 1 ( $\mathrm{p} \Delta \mathrm{P} 1 \Delta \mathrm{RAmycCAT}$ ) had no significant effect on transactivation. Since the Myb-binding site between the TATA box and P2 is located in an important regulatory region, where binding of general transcription factors like TATA factors takes place, it seemed possible that binding of c-Myb at this site caused the transactivation effects of the various $c$-myc reporter plasmids with Myb-expressing constructs. Therefore, point mutations of this Myb-binding site

Fig.2. (A) Map of the c-myc reporter plasmids used for transactivation studies. The names of the plasmids are indicated on the right site. Deleted sequences are indicated by recessed lines. P1, P2: c-myc promoters; open boxes: Myb-binding sites; hatched boxes, mutated Myb-binding site; PA: inserted poly A-sequence; C: ClaI, K: KpnI, S: SmaI, Sc: Scal, X: Xhol, R: RsrII, A: AvaI. (B) Diagram of the transactivation effects of the Myb-expressing effector plasmids with the c-myc reporter plasmids. Co-transfections and CAT assays were performed in the case of $\mathrm{p} 2.3$ mycCAT with the control plasmid pECE, that expressed no protein, the effector plasmids pHM1, pHM5 (expressing p75 c-Myb and p42 c-Myb, respectively; AA: amino acid residues) (17) and pGM5, a construct in which the DNAbinding domain of $\mathrm{p} 42 \mathrm{c}-\mathrm{Myb}$ was replaced by the DNA-binding domain of GAL4 (15). All other reporter plasmids are co-transfected with pECE and pHM5 in parallel. Conversion of chloramphenicol is derived from solubilized butyrylated forms as described in Materials and methods. The transactivation effects are given as fold transactivation based on the basal activity of each reporter plasmid determined in co-transfections and CAT assays of each reporter plasmid in parallel with the control plasmid pECE. The Figure shows the result of one representative experiment, in which all reporter plasmids were tested in parallel. Each reporter plasmid had been tested with the appropiate controls in more than four independent experiments. 


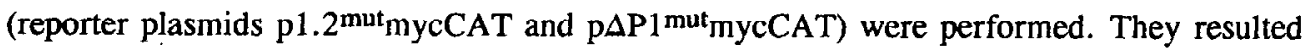
in transactivation effects that were comparable to these obtained with the respective reporter plasmids without mutations (compare p1.2mycCAT with p1.2 mut $_{\text {mycCAT }}$ and $\mathrm{p} \triangle \mathrm{P} 1$ mycCAT with $\mathrm{p} \Delta \mathrm{P} 1^{\mathrm{mut}}$ mycCAT). These results indicate that the region between TATA box and P2 is not responsible for the transactivation effects of c-Myb proteins on c-myc.

In order to cxclude that there were transcription start sites outside the $c$-myc sequences, a poly A-tail derived from SV40 was inserted into the full-length c-myc upstream region. The resulting plasmid p2.3PAmycCAT showed only a slight reduction of the transactivation effect compared to its control p2.3mycCAT. Therefore this possibility was excluded.

Finally we deleted the c-myc promoters $\mathrm{P} 2$ and both, P1 plus P2, from the full-length upstream regulatory region of c-myc (p2.3 $\mathrm{P} 2$ mycCAT and $\mathrm{p} 2.3 \Delta \mathrm{P} 1 \Delta \mathrm{P} 2 \mathrm{mycCAT})$ and tested these in co-transfection assays. They revealed that $\mathrm{P} 2$ was essential for the transactivation effect of the $\mathrm{c}-\mathrm{Myb}$ proteins on $\mathrm{c}$-myc because transactivation was completely abolished (Fig.2B).

Furthermore, we deleted a large fragment from the upstream regulatory region of c-myc (p2.3 $\mathrm{KX}$ mycCAT) leading in turn to a strong transactivation of $36 \mathrm{fold}$. This phenomenon can be most easily explained by the assumption that negative regulatory sequences are located at the deleted fragment $(24,27)$.

Co-transfections of the effector plasmid pGM5, expressing the GAL4-Myb fusion protein with all of these reporter plasmids led to weak transactivation effects. Since these cotransfections resulted in nearly the same transactivation effects with all of the c-myc reporter plasmids, only the data of p2.3mycCAT is shown in Fig.2B as a representative result. This result proves that the DNA binding domain of the c-Myb protein is essential for transactivation of c-myc.

\section{DISCUSSION}

The transactivation analysis of various $c$-myc reporter plasmids shown here indicates that expression of $\mathrm{c}-\mathrm{myc}$ can be enhanced by $\mathrm{c}-\mathrm{Myb}$ proteins with intact DNA binding domains. This transactivation effect does not depend on the presence of Myb-binding sites upstream of the c-myc promoter region since deletions and mutations of these Myb-binding sites did not diminish the effect. Thus, positive transactivation depends on the presence of sequences surrounding the c-myc promoter P2 located in exon 1.

It has been shown that the region upstream of $\mathrm{P} 2$ (and including $\mathrm{P} 2$ ) is responsible for the main transcriptional activity of the c-myc gene (28). A few proteins have been identified so far which bind to the region upstream of P2, for example MEla1 and ME1a2 (29) and E2F (30). Especially the binding site of E2F is essential for c-myc transcription (31). One possibility for the mechanism of the c-myc transactivation by $\mathrm{c}-\mathrm{Myb}$ proteins could therefore be, that the $\mathrm{c}-\mathrm{Myb}$ protein acts indirect by enhancing the expression of one of the transcription factors which bind at the region upstream of P2, e.g. E2F.

In the case of the hsp70 promoter Klempnauer et al. (19) have shown that the DNA binding 
domain of $\mathrm{v}-\mathrm{Myb}$ is dispensable for transactivation. As c-myc can only be significantly transactivated by a Myb protein which contains its DNA binding domain, it can be concluded that c-myc is transactivated by $\mathrm{c}-\mathrm{Myb}$ proteins in a way unlike the hsp70 promoter. One recently described v-Myb-regulated gene, a ribonuclease A-related gene (32), is another example for a v-Myb-regulated gene which can be transactivated by $\mathrm{v}-\mathrm{Myb}$ without the involvement of Myb-specific DNA binding sequences. In that case it is not known whether or not the DNA binding domain of the v-Myb protein was dispensable for transactivation.

It is obvious that the ability of Myb proteins to transactivate depends on properties of the respective promoter. The HIV-LTR contains some Myb-binding sites and can be transactivated by Myb proteins (33), whereas the MMTV-LTR shows no transactivation by Myb in spite of containing strong Myb-binding sites (Kalkbrenner et al., unpublished observations). In the case of the SV40 promoter strong transactivation effects are only detectable when multimerized Myb-binding sites are inserted upstream of this promoter (34). These differences between various promoters with regard to their transactivation by Myb proteins could be due to the specific transcription factors binding near the respective promoter, creating Myb sensitive or insensitive promoters. The differences between the transactivation effects of the various c-myc reporter plasmids described here could thus be explaincd on the basis of the composition of the factors on each promoter fragment.

In addition it can be speculated that the DNA binding domain of c-Myb may have other functions than binding to DNA, e.g. it may be involved in interaction with other transcription factors (35). This interaction may be similarly important for gene regulation by $\mathrm{c}-\mathrm{Myb}$ as direct Myb-DNA interaction. This model raises the possibility that $\mathrm{c}$-myc could be transactivated by an interaction of the DNA-binding domain of c-Myb with the transcription factors which bind in the region upstream of the promoter P2.

\section{ACKNOWLEDGMENTS}

This work was supported by Dr. Mildred Scheel Stiftung (F66) and the Deutsche Forschungsgemeinschaft and the Max-Planck-Society.

\section{REFERENCES}

1. Gonda, T.J., and Metcalf, D. (1984) Nature 310, 249-251.

2. Sheiness, D., and Gardinier, M. (1984) Mol. Cell. Biol. 4, 1206-1212.

3. Duprey, S.P., and Boettiger, D. (1985) Proc. Natl. Acad. Sci. USA, 82, 6937-6941.

4. Thompson, C.B., Challoner, P.B., Neiman, P.E., and Groudine, M. (1986) Nature 319, 374-380.

5. Coppola, J.A., and Cole, M.D. (1986) Nature 320, 760-763.

6. Clarke, M.F., Kukowska-Latallo, J.F., Westin, E.,Smith, M., and Prochownik, E.V. (1988) Mol. Cell. Biol. 8, 884-892.

7. Gewirtz, A.M., and Calabretta, B. (1988) Science 242, 1303-1306.

8. Anfossi, G., Gewirtz, A.M., and Calabretta, B. (1989) Proc. Natl. Acad. Sci. USA 86, 3379-3383.

9. Prochownik, E.V., Kukowska, J., and Rodgers, C. (1988) Mol. Cell. Biol. 8, 36833695.

10. Holt, J.T., Redner, R.L., and Nienhuis, A.W. (1988) Mol. Cell. Biol. 8, 963-973.

11. Evans, J.L., Moore, T.L., Kuehl, W.M., Bender, T., , and Pan-Yun Ting, J. (1990) Mol. Cell. Biol. 10, 5747-5752. 
12. Spencer, C.A and Groudine, M. (1991) Adv. Cancer Res. 56, 1-48.

13. Sakura, H., Kanei-Ishii, C., Nagase, T., Nakagoshi, H., Gonda, T.J., and Ishii, S. (1989) Proc. Natl. Acad. Sci. 86, 5758-5762.

14. Weston, K., and Bishop, J.M. (1989) Cell 58, 85-93.

15. Kalkbrenner, F., Guehmann, S., and Moelling, K. (1990) Oncogene 5, 657-661.

16. Biedenkapp, H., Borgmeyer, U., Sippel, A.E., and Klempnauer, K.H. (1988) Nature $335,835-837$.

17. Zobel, A., Kalkbrenner, F., Guehmann, S., Vorbrueggen, G., Nawrath, M., and Moelling, K. (1991) Oncogene 6, 1397-1407.

18. Howc, K.M., and Watson, R.J. (1991) Nucleic Acids Res. 19, 3913-3919.

19. Klempnauer, K.H., Amold, H., and Biedenkapp, H. (1989) Genes Dev. 3, 15821589.

20. Ness, S.A., Marknell, A., and Graf, T. (1989) Cell 59, 1115-1125.

21. Nishina, Y., Nakagoshi, H., Imamoto, F., Gonda, T.J., and Ishii, S. (1989) Nucleic Acids Res. 17, 107-117.

22. Ibanez, C.E., and Lipsick, J.S. (1990) Mol. Cell. Biol. 10, 2285-2293.

23. Ellis, L., Clauser, E., Morgan, D.O., Edery, M., Roth, R.A., and Rutter, W.J. (1986) Cell 45, 721-732.

24. Hay, N., Bishop, J.M., and Levens, D. (1987) Genes Dev. 1, 659-671.

25. Graham, F.L., and van der Eb, A.J. (1973) Virology 52, 456-467.

26. Seed, B., and Sheen, J.Y. (1988) Gene 67, 271-277.

27. Hay, N., Takimoto, M., and Bishop, J.M. (1989) Genes Dev. 3, 293-303.

28. Hall, D.J. (1990) Oncogene 5, 47-54.

29. Asselin, C., Nepveu, A., and Marcu, K.B. (1989) Oncogene 4, 549-558.

30. Kovesdi, I., Reichel, R., and Nevins, J.R. (1986) Cell 45, 219-228.

31. Thalmeier, K., Synovzik, H., Mertz, R., Winnacker, E.L., and Lipp, M. (1989) Genes Dev. 3, $527-536$.

32. Nakano, T., and Graf, T. (1992) Oncogene 7, 527-534.

33. Dasgupta, P., Linnenbach, A.J., Giaccia, A.J., Stamato, T.D., and Reddy, E.P. (1989) Oncogene 4, 1201-1205.

34. Nakagoshi, H., Nagase, T., Kanei-Ishii, C., Ueno, Y., and Ishii, I. (1990) J. Biol. Chem. 265, 3479-3483.

35. Frampton, J., Gibson, T.J., Ness, S.A., Döderlein, G., and Graf, T. (1991) Protein Engineering 4, 891-901. 